\title{
Pembentukan Personal Branding K-pop Influencer Melalui Media Sosial Instagram (Studi Kasus pada Akun Instagram @ Kimdarlings)
}

\author{
Muhammad Fauzan Azhar, Septia Winduwati \\ alfauzanazhar@gmail.com,septiaw@fikom.untar.ac.id
}

Fakultas Ilmu Komunikasi Universitas Tarumanagara, Jakarta.

\begin{abstract}
This study will discusses about the personal branding of the influencers (@ Kimdarlings) through Instagram. Nowadays, media focuses on the existence of users by facilitating them in their activities. As for the development of the digital era, social media is used as medium for disseminating information. This led to innovation, like influencers who did their branding through social media. This study aims to determine how the formation of personal branding is used by (@Kimdarlings) as K-Pop Influencer through social media Instagram. This study used the concepts of personal branding, influencers and social media. In this research used a descriptive qualitative approach with the case study method. The findings are the formation of @ Kimdarlings personal branding has seven personal branding concepts including specialization (@Kimdarlings as K-Pop enthusiasts has only been a fan of one fandom), personality (character building as a splashy or cheerful person on Instagram), differences (fangirling contents as a differentiation from other influencers), visible (@Kimdarlings consistency of doing cover dance from Korean boybands and girl bands publicly and continuously), unity (the personal life of @Kimdarlings work in line with the brand she formed),persistence (based on her principle, she only uploading contents about K-Pop), and goodwill (giving a positive image to her followers).
\end{abstract}

Keywords: influencer, instagram, personal branding.

\begin{abstract}
Abstrak
Penelitian ini membahas personal branding influencer (@Kimdarlings) melalui Instagram. Sekarang ini, media memfokuskan pada eksistensi pengguna dengan memfasilitasi mereka dalam beraktivitas. Seiring perkembangan era digital, media sosial dimanfaatkan sebagai media penyebaran informasi. Hal ini memunculkan inovasi yaitu influencer yang melakukan branding melalui Instagram. Penelitian ini bertujuan untuk mengetahui bagaimana pembentukan personal branding yang digunakan oleh (@ Kimdarlings) sebagai K-Pop Influencer melalui media sosial Instagram. Konsep yang digunakan dalam penelitian ini adalah konsep personal branding, influencer, media sosial. Metode penelitian yang digunakan adalah pendekatan kualitatif jenis deskriptif dengan metode studi kasus. Hasil temuan bahwa pembentukan personal branding @Kimdarlings sebagai K-Pop influencer melalui Instagram memiliki Tujuh konsep personal branding tersebut adalah spesialisasi (@Kimdarlings sebagai penyuka K-Pop hanya menggemari satu fandom), kepribadian (pembentukan karakter di Instagram yang heboh atau ceria), perbedaan (konten fangirling yang berbeda dengan influencer lainnya), terlihat (@Kimdarlings konsisten melakukan cover dance dari boyband dan girlband
\end{abstract}


Korea secara publik dan secara terus menerus), kesatuan (kehidupan pribadi yang @Kimdarlings bentuk sejalan dengan brand yang dibentuknya), keteguhan (berpegang teguh pada prinsip bahwa ia hanya akan mengunggah konten tentang $\mathrm{K}-\mathrm{Pop}$ ), dan nama baik (memberikan citra positif bagi pengikutnya).

Kata Kunci: influencer, instagram, personal branding

\section{Pendahuluan}

Pada era digital saat ini, media sosial merupakan hal yang sedang digemari oleh masyarakat. Media sosial merupakan media yang memfokuskan pada eksistensi pengguna dengan memfasilitasi mereka dalam beraktivitas maupun berkolaborasi karenanya media sosial dapat dilihat sebagai media online yang merupakan hubungan antar pengguna sebagai ikatan sosial (Nasrullah, 2017). Seiringnya perkembangan era digital yang memungkinkan pengguna media sosial dapat dijadikan sebagai penyebaran informasi dan konten yang kemudian melahirkan seorang yang disebut influencer. Menjadi influencer pun tidaklah mudah karena dibutuhkan proses yang panjang. Influencer yang dipilih adalah influencer di bidang K-Pop. Dikarenakan penulis tertarik dengan influencer penggemar K-Pop, serta sekarang ini demam nya culture K-Pop sudah sangat digemari oleh para khalayak di Indonesia. Popularitas Korean Wave atau yang dikenal dengan Hallyu telah merebak ke banyak negara. Tujuan dari penelitian ini Untuk mengetahui bagaimana pembentukan personal branding yang akan digunakan oleh (@Kimdarlings) sebagai K-Pop influencer melalui media sosial Instagram. Oleh karena itu peneliti mengambil judul "Pembentukan Personal Branding K-Pop Influencer melalui media sosial Instagram (Studi kasus pada Akun Instagram @Kimdarlings)". Teori yang digunakan dalam penelitian ini yaitu:

\section{Personal Branding dan konsep}

Timothy P. O'Brien, 2007 dalam Haroen. Personal branding adalah identitas yang dimiliki seseorang yang mampu menciptakan sebuah respon kepada khalayaknya mengenai kualitas dan nilai yang dimiliki oleh personal branding tersebut. (Haroen, 2014). Wasesa dalam Winduwati \& Oktavianti. Personal Branding merupakan proses seseorang menggunakan dirinya sebagai merek (brand). Personal Branding adalah bagaimana seseorang memasarkan dirinya pada khalayak secara sistematis. (Winduwati \& Oktavianti, 2019). McNally \& Speak, 2004 dalam Haroen. Personal Branding yang kuat terdapat tiga hal mendasar yang menyatu yang pertama, kekhasan yaitu seseorang yang memiliki personal branding maka akan mempunyai kekhasan yang berbeda dengan orang lain. Kedua, Relevansi yaitu seseorang yang memiliki personal branding maka akan menjelaskan sesuatu yang akan dianggap penting oleh para khalayaknya. Ketiga, Konsistensi seseorang yang memiliki personal branding akan melakukan upaya-upaya branding yang konsisten dengan berbagai cara sehingga akan terbentuk yang biasa disebut dengan brand equity (keunggulan merek). (Haroen, 2014). 
Montoya dalam Haroen (2014) menjelaskan bahwa terdapat delapan konsep pembentukan personal branding. Tetapi dalam penelitian ini influencer yang dimiliki key informan peneliti hanya memiliki tujuh konsep personal branding. Jadi, peneliti hanya akan menjelaskan ke tujuh konsep personal branding tersebut yaitu yang pertama, spesialisasi. Spesialisasi ini adalah ciri khas yang dimiliki oleh seseorang. Dengan ketepatan pada sebuah spesialisasi, akan hanya terkonsentrasi pada sebuah kekuatan untuk membedakan dengan yang lainnya, keahlian yang dimiliki, atau pencapaian tertentu untuk diri sendiri. Yang ke dua, Kepribadian dalam konsep kepribadian ini adalah sosok seseorang yang memiliki kepribadian yang positif ke khalayaknya dan cara mengekspresikan kepribadiannya tersebut kepada khalayak. Yang ke tiga, Perbedaan dalam tahap konsep selanjutnya ini adalah perbedaan yang dimiliki personal branding seseorang. Setiap seseorang yang akan membentuk brand dirinya dengan tahap konsep ini maka khalayak tersebut harus memiliki perbedaan agar khalayaknya bisa membedakan dengan yang lain.

Yang keempat, Terlihat dalam konsep ini seseorang yang terus menerus untuk membentuk personal branding nya secara konsisten supaya personal branding yang dibuatnya terlihat oleh para khalayak dan diterima oleh para khalayalak. Yang ke lima, tahap kesatuan yaitu dengan kehidupan pribadinya seseorang terhadap brand yang telah ia buat maka harus sejalan atau harus sesuai. Karena jika seseorang tersebut tidak sejalan dengan brand yang ia buat maka kehidupan pribadi dengan brand yang dibuatnya tidak akan berjalan lancar atau tidak cocok. Yang ke enam, konsep keteguhan ini adalah bagaimana seseorang yang ingin membentuk personal branding maka perlu memakan waktu untuk membentuk brand yang telah dibuatnya. Selama proses yang dibuatnya itu terus berjalan dan berkembang maka perlulah tahapan dalam membentuk brand yang akan dibuatnya. Yang ketujuh, Nama Baik bagaimana cara seseorang yang akan membentuk personal branding nya ini membuatnya dipersepsikan secara positif bukan negatif. Bahwa seseorang akan memberikan dampak ke khalayaknya. (Soraya, 2017).

\section{Influencer}

Menurut Truten (2008) dalam Arindita, influencer adalah khalayak yang melihat seseorang sebagai yang memberikan suatu sumber informasi dan membuat interaksi antara influencer tersebut dengan khalayaknya serta akan mempengaruhi suatu keputusan terhadap produk atau jasa yang telah ditinjau oleh influencer tersebut. Media sosial saat ini membutuhkan peran terhadap influencer karena beberapa brand lebih memilih influencer di media sosial Instagram sebagai Brand Ambassador terhadap brand tersebut. Karena dapat menciptakan trend dan mendorong pengikutnya atau khalayaknya untuk membeli produk yang akan mereka promosikan. (Arindita, 2019).

\section{Media Sosial}

Dalam bukunya Nasrullah ada beberapa macam karakteristik media sosial, dari beberapa macam karakteristik ini hanya beberapa yang dimiliki oleh influencer yang menjadi bahan penelitian ini. Berikut karakteristik media sosial 
yang dimiliki oleh influencer peneliti menurut informan yang telah peneliti wawancara. Yang pertama, informasi bahwa informasi menjadi sangat penting di media sosial karena informasi akan dikonsumsi oleh khalayak melalui media sosial dan dari informasi tersebut akan disebar antar pengguna media sosial. Yang kedua, Arsip Menurut Carrol \& Romano dalam Nasrullah. Media sosial atau media baru, tidak hanya untuk memberikan informasi semata ke sesama pengguna media sosial. Tetapi juga memiliki arsip, arsip di media sosial ini fungsinya untuk menyimpan suatu yang sudah diunggah oleh pengguna media sosial, atau menaruh suatu informasi yang sudah diunggah bisa diunggah kembali oleh pengguna media sosial tersebut. (Nasrullah, 2018). Yang ketiga, Interaksi menurut Steven Graham, Gane, Beer dalam Nasrullah. Media sosial akan terbentuknya jaringan komunikasi antar pengguna. Jaringan komunikasi tersebut tidak sekedar memperluas hubungan pertemanan terhadap pengikutnya (follower) di media sosial semata, melainkan juga membangun interaksi dengan antar pengguna media sosial tersebut. (Nasrullah, 2018) Yang ke empat, konten oleh pengguna Menurut Jenkins dalam Nasrullah. Bahwa konten oleh pengguna media sosial untuk mengunggah suatu konten maka perlu adanya memberikan sebuah keterangan atau bisa disebut sebagai caption. Media sosial perlu juga untuk menyesuaikan isi konten dengan keterangan caption yang jelas supaya tidak membuat konten tersebut ambigu ke pengguna Instagram lainnya. Serta juga untuk konsisten terhadap konten yang akan dibuat lalu diunggah ke media sosial (Nasrullah, 2018). Yang kelima, Penyebaran bahwa dalam penyebaran di media sosial sangat cepat untuk para pengguna media sosial. Karena setiap unggahan di media sosial akan langsung menyebar ke seluruh pengikutnya di media sosial. Dari hasil unggahan tersebut bisa diunggah ulang dari satu khalayak ke khalayak lainnya. (Nasrullah, 2017)

\section{Instagram}

Menurut Nisrina (2015) Instagram sebagai media sosial baru dan juga cara penggunaannya mudah bagi pengguna Instagram. serta fungsi Instagram tidak hanya membagi foto yang akan diunggah oleh pengguna Instagram melainkan bisa untuk berinteraksi atau mempromosikan suatu barang/jasa. (Soraya, 2017).

\section{Metode Penelitian}

Dalam penelitian ini peneliti menggunakan pendekatan kualitatif deskriptif. Dengan penelitian kualitatif ini untuk bermaksud memahami pembentukan personal branding yang dimiliki oleh K-Pop influencer yaitu @Kimdarlings. Metode dalam penelitian ini menggunakan metode studi kasus, studi kasus adalah mencoba untuk menjelaskan keputusan tentang studi tersebut mengapa untuk dipilih, dan bagaimana cara untuk mengimplementasikannya serta hasil apa yang didapatkan. (Yin, 2014).

Untuk mengumpulkan data dalam penelitian ini dengan menggunakan metode data primer, data sekunder, studi kepustakaan, wawancara mendalam serta studi dokumentasi. Narasumber peneliti yang diwawancarai 
1. @Kimdarlings K-Pop Influencer (Key informan)

2. Via salah satu pengikutnya @ Kimdarlings (Informan)

3. Nama yang disamarkan salah satu pengikutnya @Kimdarlings (Informan)

Analisis data yang digunakan dalam penelitian ini menurut Miles dan Huberman dalam Sugiyono. Bahwa dalam analisis data kualitatif dilakukan secara interaktif dan berlangsung dalam analisis data, yaitu dengan data reduction, data display, dan conclusion drawing/verification. (Sugiyono, 2016). peneliti menganalisis data tersebut dengan menggunakan reduksi data dengan memilih data yang terkait dengan penelitian. Selanjutnya peneliti melakukan penyajian data dengan mengkategorikan data yang didapat oleh peneliti. Yang terakhir adalah menganalisis dari data tersebut dengan membuat kesimpulan dengan data yang sudah diperoleh oleh peneliti. Dalam penelitian ini perlu keabsahan data dalam Moleong, ada empat kriteria yang digunakan yaitu derajat kepercayaan (credibility), keteralihan (transferability), kebergantungan (dependability), dan kepastian (confirmability). (Moleong, 2017) Peneliti menggunakan teknik triangulasi dalam penelitian ini untuk menguji keabsahan data triangulasi. Menurut Susan Stainback dalam Sugiyono Tujuan dari triangulasi ini bukan untuk mencari kebenaran tentang beberapa fenomena, tetapi akan lebih pada peningkatan pemahaman peneliti terhadap apa yang telah ditemukan dalam penelitian ini. (Sugiyono, 2016:85). Jadi, dengan peneliti menggunakan teknik triangulasi maka peneliti bisa mengumpulkan beberapa data pendukung untuk menjadi bahan data penelitian.

\section{Hasil Temuan dan Diskusi}

Hasil penelitian yang didapatkan oleh peneliti adalah bahwa @ Kimdarlings hanya memiliki tujuh konsep personal branding yang dimilikinya. Menurut Montoya dalam Haroen (2014) ketujuh konsep personal branding yang @ Kimdarlings miliki.

\section{Spesialisasi (The Law of Specialization)}

@Kimdarlings sebagai influencer di bidang K-Pop hanya menggemari satu fandom sehingga hal tersebut mempengaruhi proses pembuatan kontennya. Ketika akan mengunggah konten ke media sosial Instagramnya, maka ia cenderung akan mengutamakan konten-konten yang memuat tentang boyband EXO.

2. Kepribadian ((The Law of Personality)

@ Kimdarlings menyatakan bahwa ia membangun karakternya sebagai seseorang yang heboh atau ceria. Hal tersebut ia bentuk melalui konten-kontennya yang diunggah melalui media sosial Instagram.

\section{Perbedaan (The Law of Distinctiveness)}

@Kimdarlings memiliki sebuah perbedaan yang membuatnya berbeda dengan influencer lainnya yaitu konten-konten fangirling yang ia buat sebagai diferensiasi karena tipe konten tersebut masih cukup jarang dibuat oleh influencer lain yang juga menggemari K-Pop sepertinya. 


\section{Terlihat (The Law of Visibility)}

Keterlihatan@Kimdarlings bisa ditinjau dari tingkat konsistensi yang dimilikinya dalam mengunggah konten. Adapun konten tersebut berupa video dance cover dari boyband dan girlband Korea yang dalam prosesnya ia lakukan di hadapan publik dan terjadi secara terus-menerus.

\section{Kesatuan (The Law of Unity)}

@Kimdarlings mengemukakan bahwa ia memiliki keseimbangan antara kehidupan pribadi dengan brand yang dibentuk. Keseimbangan yang dimaksud olehnya adalah ia bisa menerapkan brand yang telah dibentuknya itu tidak hanya di media sosial Instagram tetapi juga dalam kehidupannya sehari-hari. Brand yang dibentuk olehnya bisa berjalan seiring dengan gaya hidupnya.

\section{Keteguhan (The Law of Persistence)}

@Kimdarlings merupakan influencer berpegang teguh dengan prinsip yang ia miliki yaitu untuk selalu mengunggah konten-konten mengenai K-Pop. Seluruh konten yang ia unggah di Instagram selalu berkaitan dengan K-Pop.

\section{Nama Baik (The Law of Goodwill)}

@ Kimdarlings mengemukakan bahwa untuk menjadi seorang influencer dikenal sebagai seseorang yang memiliki citra positif kepada pengikut. Hal ini dibuktikan melalui pernyataan dari pengikut @ Kimdarlings di Instagram yang menganggap bahwa influencer tersebut memiliki citra yang baik.

Menurut Truten (2008) dalam Arindita, influencer adalah khalayak yang melihat seseorang sebagai yang memberikan suatu sumber informasi dan membuat interaksi antara influencer tersebut dengan khalayaknya serta akan mempengaruhi suatu keputusan terhadap produk atau jasa yang telah ditinjau oleh influencer tersebut. Berdasarkan pendapat dari pengikutnya @ Kimdarlings yang bernama Via. Ia menjelaskan bahwa @Kimdarlings sebagai influencer tidak hanya memberikan informasi ke khalayaknya tetapi ia juga sebagai influencer memiliki talenta dan itu menjadi kelebihan bagi @Kimdarlings.

Dalam Nasrullah ada beberapa macam karakteristik media sosial (Nasrullah, 2017). Berikut merupakan karakteristik media sosial yang dimiliki oleh @Kimdarlings menurut informan @ Kimdarlings yang telah peneliti wawancara. Yang pertama, dalam pernyataannya informan A mengatakan bahwa @ Kimdarlings dalam berinteraksi melalui media sosial online kepada pengikutnya juga memberikan informasi tentang K-Pop yang ia ketahui atau halhal yang sedang booming saat ini. Yang ke dua, dalam pernyataan dari pengikut Instagram @Kimdarlings, Via menyatakan bahwa dalam arsip media sosial Instagram@Kimdarlings sebagai influencer tidak hanya memberikan informasi tentang K-Pop saja kepada khalayak melainkan juga melakukan fangirling. Fangirling adalah istilah yang digunakan untuk menjelaskan mengenai seseorang yang mengunggah tentang idola kesukaannya dan secara tidak langsung akan berimajinasi tentang idola yang digemarinya. Hal ini berkaitan dengan konsep personal branding yang dimiliki oleh @Kimdarlings yaitu perbedaan (The Law of Distinctiveness). Yang ketiga adalah interaksi, dalam pernyataanya informan A menjelaskan bahwa interaksi @Kimdarlings dengan followersnya di media sosial Instagram, pengikut dapat membuat kesimpulan bahwa ia adalah seorang yang 
ceria terhadap. Interaksi yang dilakukan @Kimdarlings dengan pengikutnya adalah bertukar informasi mengenai boyband EXO. Hal ini dikarenakan @ Kimdarlings merupakan penggemar berat boyband asal Korea tersebut. Yang keempat adalah penilaian konten oleh pengikut, dalam pernyataannya informan A menyatakan bahwa@Kimdarlings sebagai influencer merupakan seorang yang konsisten terhadap konten yang dibuatnya seperti pada konsep personal branding yang dimilikinya yaitu terlihat (The Law of Visibility). Dalam media sosial Instagramnya @Kimdarlings sudah cukup konsisten di Instagram karena keaktifannya dalam memberikan informasi tentang EXO kepada pengikutnya. Yang kelima penyebaran, dalam pernyataanya informan A menjelaskan bahwa @Kimdarlings menyebarkan budaya K-Pop sebagai hal yang positif seperti konsep personal branding @ Kimdarlings yang dimilikinya yaitu nama baik (The Law of Goodwill).

Berdasarkan konsep ini, @ Kimdarlings menyebarkan informasi K-Pop itu dengan cara yang positif. Seperti yang sudah dijelaskan menurut (Nisrina 2015) mengenai Instagram. @Kimdarlings sebagai influencer menyebarkan kontenkonten yang menarik. Adapun pendapat dari pengikutnya @ Kimdarlings menjelaskan bahwa foto yang diunggah oleh @Kimdarlings di Instagram tidak terlihat mempromosikan suatu brand yang ia dapat seperti influencer lainnya secara terang-terangan (hard-selling). @Kimdarlings sebagai influencer menggunakan Instagram untuk membuat konten yang cukup menarik selain dari promosi brand tersebut. (Soraya, 2017).

\section{Simpulan}

@ Kimdarlings memiliki tujuh konsep personal branding yaitu spesialisasi (adalah @Kimdarlings sebagai K-Pop influencer hanya menggemari satu fandom untuk mengutamakan konten yang ia unggah di Instagram). Kepribadian (adalah pembentukan karakter yang heboh dan ceria yang dibuatnya melalui Instagram). Perbedaan adalah (@Kimdarlings sebagai influencer memiliki konten fangirling yang cukup berbeda dengan influencer lain). Terlihat adalah (@Kimdarlings konsisten dalam menirukan tarian dari boyband dan girlband Korea secara publik dan secara terus menerus). Kesatuan (adalah kehidupan pribadi yang @Kimdarlings bentuk sejalan dengan brand yang dibentuknya). Keteguhan (adalah berpegang teguh pada prinsip bahwa ia hanya akan mengunggah konten tentang K-Pop). Nama baik (adalah berdasarkan dari pengikutnya @Kimdarlings sebagai seseorang yang memiliki citra positif kepada pengikut). Bagi influencer untuk terus mengunggah lebih banyak lagi konten yang positif dan selalu konsisten terhadap bidang yang digelutinya supaya semakin lebih banyak orang yang terinspirasi.

\section{Ucapan Terima Kasih}

Penyusunan skripsi ini dapat terlaksana dan berjalan lancar. Oleh karena itu peneliti ingin mengucapkan terima kasih kepada semua pihak yang terlibat dalam penyusunan skripsi ini. Kepada @ Kimdarlings K-Pop influencer (Key 
informan), Via salah satu pengikutnya @Kimdarlings (Informan), Nama yang disamarkan salah satu pengikutnya @Kimdarlings (Informan). Kepada kedua Orang Tua dan Keluarga serta Teman yang telah menyemangati dan memberikan dukungan untuk menyelesaikan penyusunan skripsi.

\section{Daftar Pustaka}

Arindita, Ruvira. (2019) Personal Branding MOM-Influencer Dan Representasi Ibu Millennial Di Media Sosial. Jurnal E-Komunikasi VOL. 18 NO.1 Tahun 2019 Program Studi Ilmu Komunikasi, Universitas Al Azhar Indonesia, Jakarta. Agustus 30, 2019 Terarsip di: file:///D:/Tugas\%20kuliah\%20

ilkom/FIKOM\%20SEMESTER\%207/SKRIPSI/JURNAL/722-1663-1PB.pdf.

Haroen, Dewi. (2014). Personal Branding. Jakarta: PT Gramedia Pustaka Utama. Moleong, Lexy J. (2017). Metodologi Penelitian Kualitatif. Bandung: PT Remaja Rosdakarya.

Nasrullah, Rulli. (2017). Media Sosial Perspektif Komunikasi, Budaya, dan Sosioteknologi. Bandung: Simbiosa Rekatama Media.

Soraya, Iin. (2017) Personal Branding Laudya Cynthia Bella Melalui Instagram (Studi Deskriptif Kualitatif Pada Akun Instagram @Bandungmakuta). Jurnal E-Komunikasi VOL 8. NO.2 Tahun 2017 Program Studi Periklanan/AKOM BSI Jakarta Akademi Komunikasi Bina Sarana Informatika Jakarta.Oktober 1, $2019 \quad$ Terarsip di: file:///D:/Tugas\%20kuliah\%20ilkom/FIKOM\%20SEMESTER\%207/SKRI PSI/JURNAL/2654-6881-2-PB.pdf.

Sugiyono. (2016). Memahami Penelitian Kualitatif. Bandung: ALFABETA, cv.

Winduwati, Septia., \& Oktavianti, Roswita. (2019). Pentingnya Kemampuan Personal Branding di Era Digital. Yogyakarta: Buku Litera.

Yin, Robert K. (2014). Studi Kasus Desain \& Metode. Jakarta: Rajawali Pers. 